\title{
PATTERN OF MAXILLOFACIAL INJURIES IN PEDIATRIC PATIENTS - A HOSPITAL BASED RETROSPECTIVE STUDY
}

\author{
Mishra $R^{1^{*}}$, Yadav $D^{1}$, Kandel $L^{1}$, Tripathi $S^{1}$, Pahari $B^{1}$, Shubham $S^{2}$, Gautam $N^{3}$
}

\begin{abstract}
Affiliation
1. Department of Oral and Maxillofacial Surgery, UCMS College of Dental Surgery, Bhairahawa, Rupandehi, Nepal;

2. Department of Conservative Dentistry and Endodontics, UCMS College of Dental Surgery, Bhairahawa, Rupandehi, Nepal;

3. Department of Biochemistry, Universal College of Medical Sciences, Bhairahawa, Rupandehi, Nepal;
\end{abstract}

\section{ARTICLE INFO}

Received : 25 July, 2020

Accepted : 25 November, 2020

Published : 22 December, 2020

(C) Authors retain copyright and grant the journal right of first publication with the work simultaneously licensed under Creative Commons Attribution License CC - BY 4.0 that allows others to share the work with an acknowledgment of the work's authorship and initial publication in this journal.

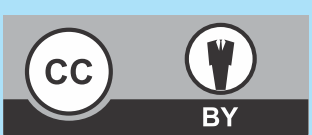

ORA 209

DOI: https://doi.org/10.3126/bjhs.v5i3.33700

\section{* Corresponding Author}

Dr. Ravish Mishra

Department of Oral and Maxillofacial Surgery, UCMS College of Dental Surgery

Bhairahawa, Rupandehi, Nepal

Email ID: drravishmishra84@gmail.com

ORCID ID: https://orcid.org/0000-0000-0001-7368-099X

\section{Citation}

Mishra R, Yadav D, Kandel L, Tripathi S, Pahari B, Shubham S, Gautam N. Pattern of Maxillofacial Injuries in Pediatric Patients - A Hospital Based Retrospective Study. BJHS 2020;5(3)13. 1210-1214.

\section{ABSTRACT}

\section{Introduction}

Maxillofacial injuries are less frequent in children than adults and are more often minimally displaced. Literature reveals that the incidence of maxillofacial injuries accounts for $1 \%-14.7 \%$ in children below age 16 years. There is lack of information on epidemiological data for pediatric maxillofacial injury from Nepal.

\section{Objectives}

The objective of the study was to determine the pattern of maxillofacial injuries in the pediatric population who had been treated in one of the tertiary level hospitals in western Nepal.

\section{Methodology}

Among 303 cases of maxillofacial trauma registered from March 2017 to February 2019 at Universal College of Medical Sciences, College of Dental Surgery, Bhairahawa, Rupandehi, Nepal; 57 cases of pediatric maxillofacial injuries that were admitted and received treatment were enrolled in the study. Parameters recorded were demographic data, mode of injury, the pattern of maxillofacial injuries and treatment provided.

\section{Result}

Majority of patients were males (66.67\%) among which 51\% were adolescents (12-16 years). The mode of injury was road traffic accidents (77.1\%) in most cases. Mandibular fractures were commonly seen in which parasymphysis region (40\%) was common anatomic site. Most of the injured patients (45.7\%) were managed with open reduction and internal fixation. Post-operative results were uneventful.

\section{Conclusion}

The road traffic accident was the predominant mode for injury. Mandible is one of the most commonly involved bones to get a fracture. Good traffic sense needs to be imbibed and developed by the government as well as the public to prevent road traffic accidents. In addition, children need to carry out their outdoor activities under adult supervision.

\section{KEYWORDS}

Mandible, maxillofacial injuries, pediatric, retrospective 


\section{INTRODUCTION}

Trauma is defined as a bodily injury resulting from external force and is one of the major causes of morbidity and mortality in the pediatric population. Maxillofacial injuries in children occur less frequently than adults and are more often minimally displaced which is due to dense adipose tissue layer that covers the more elastic bones and the suture lines are more flexible. ${ }^{1,2}$ Also, the prominence of the buccal fat pad disperses the impact over a wider region, hence more force is required to fracture the bone in a child compared to adults. ${ }^{1}$

Overall data shows majority accounts for dentoalveolar fractures and soft tissue injuries, whereas the frequency of facial bone fractures is considerably low. In addition, bone is more elastic which is due to the presence of developing tooth buds within the jaws, less mineralization of bone and lack of sinus pneumatization. ${ }^{3}$

Diagnosis is more difficult than in adults and fractures are easily overlooked. The retruded position of the face in comparision to the protecting skull is an important reason for the lower incidence of maxillofacial injuries in the pediatric population. There are significant differences between adults and children in anatomic, physiologic and psychologic development, so not only do the consequences of trauma differ, but the management techniques should be modified to address the child's stage of anatomic, physiologic, or psychologic development. The literature indicates that as the age of patients increases, the patterns of fractures progressively resemble that of adult patients. ${ }^{2,4}$

It has been well documented that the incidence of maxillofacial injuries in pediatric patients accounts for $1 \%-14.7 \%$ in children below the age of 16 years and $0.87-1 \%$ in those younger than 5 years..$^{5-8}$ The incidence of maxillofacial fractures in pediatric population in India is $5.5 \%$. ${ }^{9}$ Soft tissue injuries in pediatric population are most often overlooked however, they are seen in approximately $70 \%$ of children. ${ }^{7,8}$ A review of the literature showed lack of information on epidemiological data for pediatric maxillofacial injuries from Nepal.

The present study intends to determine the pattern of maxillofacial injuries in pediatric population who had been treated in one of the tertiary level hospitals in western Nepal.

\section{METHODOLOGY}

It was a hospital based retrospective study that was approved by the Institutional Review Committee (IRC) of Universal College of Medical Sciences (UCMS), Bhairahawa, Rupandehi, Nepal (IRC number 027/20).

Among 303 cases of maxillofacial injuries registered from March 2017 to February 2019 at UCMS, College of Dental Surgery, Bhairahawa, Rupandehi, Nepal; 57 cases of maxillofacial injuries between the age group 0-16 years that were admitted and treated were enrolled in the study. Parameters recorded were demographic details, mode of injuries, pattern of maxillofacial injuries and the treatment provided. Data collection regarding the pattern of injury was based upon the records of clinical examination and radiographic findings including computed tomographic scan which was done when required. Outpatients, patients with incomplete medical record information and patients with prior treatment were excluded from study.

Data were entered in Microsoft Excel 2007 and analyzed by means of Statistical Package for Social Sciences (SPSS 18.0 for Windows, SPSS Inc.) for descriptive statistics.

\section{RESULTS}

Pediatric maxillofacial injuries were seen in $18.8 \%$ (57 cases out 303 cases). The selected group included 38 males $(66.67 \%)$ and 19 females (33.33\%) as shown in figure 1. According to US FDA (Food and Drug Administration) age group for the pediatric population have been divided into the following categories: neonates (0-1 months), infants (1 month-2 years), children (2-12 years) and adolescent (1216years). ${ }^{10}$ A total of 29 patients (51\%) with maxillofacial injuries were adolescents followed by 20 patients (35\%) who were children. No injury was seen in neonates as shown in table 1 . The most common mode of injury in pediatric population was road traffic accident $(77.1 \%)$ followed by fall injury (15.8\%) (Table 2). Day wise distribution showed most injuries were seen on Wednesday $(28.07 \%)$ followed by Monday (26.32\%) (Figure 2). The month wise distribution showed November and December (15.79\%) with the maximum number of injuries followed by January, February and July (10.53\%) (Figure 3). There were 68 anatomic site wise maxillofacial injuries in 57 patients. Mandibular fracture $(60.3 \%)$ was the most common maxillofacial injury followed by dentoalveolar fracture $(17.6 \%)$ and soft tissue injuries (14.7\%) (Table 3). There were 65 site of mandibular fracture in 57 patients. Parasymphysis fracture (40\%) was the most common type of fracture followed by angle (23.1\%) and condyle (15.4\%) on the basis of anatomic site wise distribution of mandibular fracture (Table 4). Most patients with maxillofacial injuries were managed with open reduction internal fixation (ORIF) (45.7\%) followed by circum-mandibular wiring (CMW) $(33.3 \%)$ as shown in table 5 . Soft tissue injuries patients were treated with suturing in $17.5 \%$ and patients with isolated dentoalveolar fractures were treated with splints in $3.5 \%$. Pediatric patients with isolated or combined condylar fractures were treated with short term intermaxillary fixation (IMF) and early mobilization. Post-operative results for patients treated both conservatively and surgically were uneventful without any potential complications.

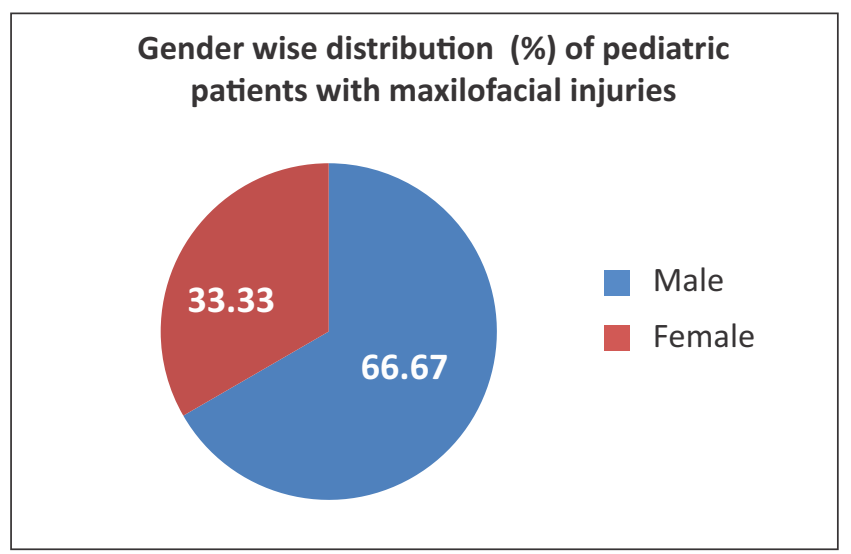

Figure 1: Gender wise distribution of patients 
Table 1: Age wise distribution of patients with maxillofacial injuries

\begin{tabular}{lc} 
Age & Number (Frequency \%) \\
\hline $0-1$ month & 0 \\
1 month -2 years & $8(14)$ \\
2 years- 12 years & $20(35)$ \\
12 years- 16 years & $29(51)$ \\
\hline
\end{tabular}

\section{Table 2: Mode of injuries}

Mode of Injury

Number (Frequency\%)

$\begin{array}{ll}\text { RTA } & 44(77.1) \\ \text { Fall injury } & 9(15.8) \\ \text { Sports injury } & 2(3.5) \\ \text { Physical assault } & 1(1.8) \\ \text { Machinery injury } & 1(1.8)\end{array}$

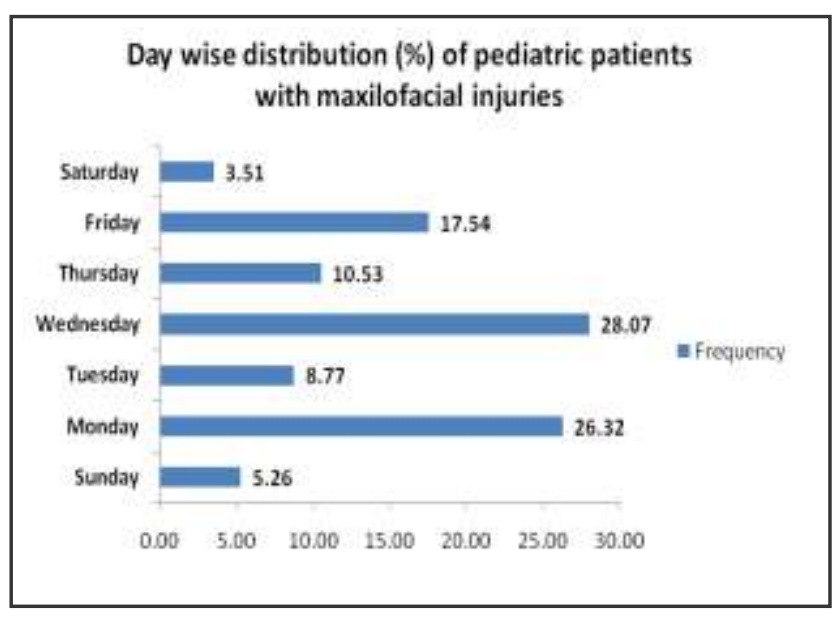

Figure 2: Day wise distribution of patients with maxillofacial injuries

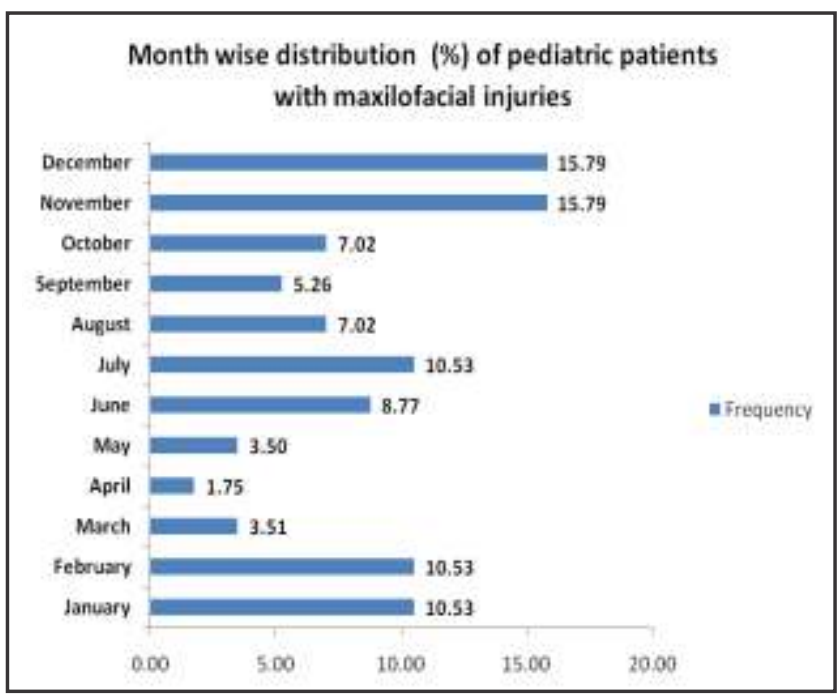

Figure 3: Month wise distribution of patients with maxillofacial injuries
Table 3: Anatomic site wise distribution of maxillofacial injuries

Site (Number)

Frequency $\%$

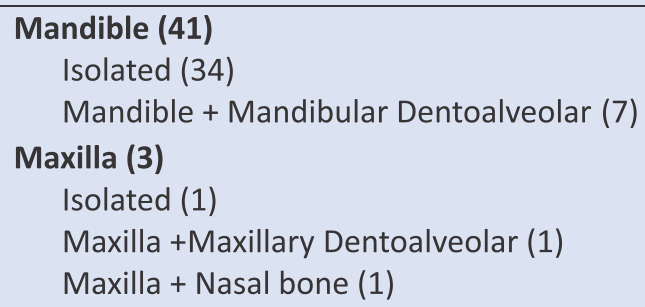

Isolated (1)

Maxilla +Maxillary Dentoalveolar (1)

Maxilla + Nasal bone (1)

Nasal bone (2)

Isolated (1)

60.3

Maxilla + Nasal bone (1)

Dentoalveolar (12)

Maxillary Dentoalveolar (4)

Mandible + Mandibular Dentoalveolar (7)

Maxilla + Maxillary Dentoalveolar (1)

Soft tissue (10)

Table 4: Anatomic site wise distribution of mandibular fractures

Site (Number) Frequency \%

Symphysis (4)

Isolated (2)

Symphysis + Bilateral condyle (2)

Parasymphysis (26)

40

Isolated (13)

Parasymphysis + Condyle (3)

Parasymphysis + Angle (10)

Body (3)

Angle (15)

Isolated (5)

Parasymphysis + Angle (10)

Condyle (10)

Isolated (3)

Parasymphysis + Condyle (3)

Symphysis + Bilateral condyle (4)

Dentoalveolar (7)

10.8

Table 5: Treatment provided to pediatric patients

Treatment provided

Number (Frequency\%)

ORIF

$26(45.7)$

CMW

$19(33.3)$

Splinting

$2(3.5)$

Suturing

$10(17.5)$

\section{DISCUSSION}

Pediatric injuries are an emerging global public health concern. Hundreds of thousands of children die every year from injuries or violence worldwide, and millions of others 
suffer the consequences of non-fatal injuries. The present study comprised of complete medical records of pediatric patients $(n=57)$ with maxillofacial injuries who had been admitted and treated within stipulated time period in Department of Oral and Maxillofacial Surgery, UCMS College of Dental Surgery, Bhairahawa, Nepal. Out of 57 patients, 38 (66.67\%) were male and 19 (33.33\%) were female. A total of $51 \%(n=29)$ were adolescents between 12 to 16 years followed by $35 \%(n=20)$ were children between 2 to 12 years. Few patients (14\%) with maxillofacial injuries have been reported in the present study below age 2 years which in accordance with the study done by various authors. $^{1,9,11-15}$ The male predominance of the adolescent age group may be due to their more aggressive behaviour and indulgence in outdoor activities. Very less incidence of maxillofacial injuries below the age of 2 years might be due to their direct supervision under parental care and constant safeguards to limit injury.

Road traffic accidents (77.1\%) was the most common mode of injury in pediatric patients followed by fall from height and sports injury which is in coherence with the study done by Holland $\mathrm{AJ}$ et al, Bamjee $\mathrm{Y}$ et al and Posnik JC et al. ${ }^{16-18}$ Most common reason for this may be due to use of bicycles on the road, crossing the road independently without adult supervision, lack of awareness in using safety measures while riding such as helmets or any other protective covers. However, Gassner R et al, Kumarswamy SV et al, Wymann NE et al and Karim T et al found that fall from height was the most common cause of maxillofacial injuries in pediatric patients. ${ }^{9,11,13,14}$

In the present study, Monday and Wednesday were the most common days in which patients were admitted with maxillofacial injuries. Month wise distribution showed November and December with higher incidence which may be due to festival and winter holidays in these months with their more indulgence in outdoor activities.

Mandibular fractures were the most common finding in the present study. Out of 57 patients, $60.3 \%$ had mandibular fractures, $17.6 \%$ patients had dentoalveolar fractures and $14.7 \%$ had only soft tissue lacerated wounds over the face. Similar findings regarding mandibular fractures were found in the study done by Kumarswamy SV et al, Karim T et al and Qudah MA et al. ${ }^{9,14,19}$ In contrast, Holland et al found maxillary fractures as the commonest fractures in their study. ${ }^{16}$ Low incidence of maxillary fractures in our study might be due to the underdiagnosis of fractures in the maxillary region as expensive modern radiological investigations like computed tomography is required for proper diagnosis. To overcome this, detailed clinical history with thorough physical and clinical examinations should be done. In addition, most often midface fractures in pediatric populations are treated conservatively until and unless it is grossly displaced or have a functional discrepancy. Dentoalveolar fractures were the second most common variant which was in accordance with studies done by Kumarswamy et al, Gassner et al and Kambalimath et al. 9,11,20 Individual anatomic site wise mandibular fracture distribution showed parasymphysis region (40\%) to be the most prevalent type of fracture in pediatric population followed by angle (23.1\%) and condyle (15.4\%) which is similar to the study done by Ogunlewe et al. ${ }^{21}$ In contrast, Nigerian studies done by Fasola et al and Adeyemo et al revealed condylar fracture as one of the most common variant. ${ }^{22,23}$ Similar result was with the study done by Posnick JC et al. ${ }^{18}$ Symphysis and body fractures were least common in our study. This variation in individual site of the mandibular fracture distribution shows that the pattern is always multifactorial and depends upon the impact of associated variables. ${ }^{24}$

During treatment planning for pediatric patients with facial trauma, various elements must be considered. These include the age of the patient (to maximize growth and development), the anatomic site (to optimize form and function), the complexity of the injury (displacement, comminution, and the number of sites), the time elapsed since injury (ideal to treat within 4 days), concomitant injury (fitness for anesthesia and duration of surgery), and the surgical approach (closed versus open). The fixation preference will be dictated by the age, anatomic site, complexity, and approach. ${ }^{5,25,26}$

Monomandibular fixation, by means of an arch bar, acrylic splint (or stent), or thermoplastic material, may be the only acceptable alternative in situations such as the edentulous newborn with a mandibular body or symphysis fracture. This technique is particularly helpful for greenstick or minimally displaced fractures when the patient is partially edentulous (ages 5-12years). These patients generally require circummandibular wires or some form of skeletal suspension. Maxillomandibular fixation is usually maintained for 3 to 4 weeks. This fixation has the disadvantage of limiting anatomic reduction and restricting full function.

In the present study, open reduction and internal fixation (ORIF) was done in $45.7 \%$ of the patients with mandibular fractures followed by circum-mandibular wiring (CMW) in $33.3 \%$. Most of the patients with mandibular fractures were adolescents (51\%) of age group 12 to 16 years. So, the choice of treatment was ORIF with miniplates as there are no developing tooth buds inside the bone in this age group. For the patients in mixed dentition period, the most preferred treatment was CMW with the fabrication of an acrylic cap splint. ORIF provided quick and satisfactory management of fractures in pediatric patients with satisfactory outcomes.

\section{CONCLUSION}

Road traffic accidents were the predominant cause for most of the facial fractures in children followed by fall from height. The most common site of mandibular fractures was parasymphysis region. The incidence of maxillofacial injuries was predominant in males than in females. Good traffic sense needs to be imbibed and developed by the government as well as the public to prevent road traffic accidents. In addition, children need to carry their outdoor activities under adult supervision. Certain preventive measures like wearing helmets and other protective covers while riding a bicycle or during sports significantly reduces the risk of maxillofacial injuries in pediatric populations. 


\section{LIMITATIONS OF THE STUDY}

This study would have been more informative if we had included a larger number of samples with longer time frame.

\section{ACKNOWLEDGEMENT}

We would like to acknowledge our residents, staffs and interns posted in the Department of Oral and Maxillofacial
Surgery, UCMS College of Dental Surgery, Bhairahawa, Nepal for their constant support, help and cooperation during the study period.

\section{CONFLICT OFINTEREST}

The author reports no conflicts of interest in this work.

\section{FINANCIAL DISCLOSURE}

None

\section{REFERENCES}

1. Zimmermann CE, Troulis MJ, Kaban LB. Pediatric facial fractures: Recent advances in prevention, diagnosis and management. Int J Oral Maxillofac Surg. 2005; 34:823-33. DOI: 10.1016/j.ijom 2005.06.015

2. Thorén $\mathrm{H}$, Iso-Kunguas $\mathrm{P}$, Lizuka $\mathrm{T}$, Lindqvist $\mathrm{C}$, Töarnwall J. Changing Trends in causes and patterns of facial fractures in children. Oral Surg Oral Med Oral Pathol Oral Radiol Endod.2009;107:318-24. DOI: 10.1016/j.tripleo.2008.09.024

3. Costello BJ, Papadopoulos H, Ruiz R. Pediatric Cranomaxillofacial Trauma. Clin ped Emerg Med.2005; 6:32-40. DOI: 10.1016/ j.cpem.2004.12.002

4. Yeung JHH, Leung CSM, Poon WS, Cheung NK, Grahan CA, Rainer TH. Bicycle related injuries presenting to a trauma centre in Hong Kong. Injury Int J Care injured.2009;40:555-9. DOI: 10.1016/j.injury. 2008.08.015

5. Haug RH, Foss J. Maxillofacial injuries in pediatric patient. Oral Surg Oral Med Oral Pathol Oral Radiol Endod 2000; 90: 126-134. DOI: 10.1067/moe.2000.107974

6. Kaban LB. Diagnosis and treatment of fractures of the facial bones in children, 1943-1993. J Oral Maxillofac Surg. 1993; 51:722-9. DOI: 10.1016/s0278-2391(10)80409-4

7. Okoje VN, Alonge TO, Oluteye OA, Obafunke O, Denloye OO. Changing pattern of paediatric maxillofacial injuries at the accident and emergency department of the university teaching hospital, Ibadan-A four year experience. Prehosp Disaster Med. 2010; 25:603. DOI:10.1017/s1049023x0000769x

8. Kotecha S, Scannell J, Monghan A, Williams RW. A four-year retrospective study of 1,1062 patients presenting with maxillofacial emergencies at specialist paediatric hospital. $\mathrm{Br} J$ Oral Maxillofac Surg. 2008; 46:293-6. DOI: 10.1016/j.bjoms.2007.11.011

9. Kumarswamy SV, Madan N, Keerthi R, Singh DS. Pediatric injuries in maxillofacial trauma: a 5 year study. J Maxillofac Oral Surg. 2009; 8:150-153. DOI: 10.1007/s12663-009-0037-4

10. Mahmood I. Prediction of drug clearance in children: impact of allometric exponents, body weight and age. Therapeutic Drug Monitoring 2007;29(3):271-278. DOI: 10.1097/ ftd.0b013e318 $042 d 3 c 4$

11. Gassner R, Tuli T, Hachl O,Morerio R, Ulmer H. Craniomaxillofaacial trauma in children: a review of 3,385 cases with 6,060 injuries in 10 years. J Oral Maxillofac Surg. 2004;62(4):399-407. DOI: 10.1016/ j.joms.2003.05.013

12. Motamedi MH. An assessment of maxillofacial fractures: a 5 year study of 237 patients. J Oral Maxillofac Surg. 2003; 61:61. DOI:10.1053/joms.2003.50049
13. Waymann NE, Holzle A, IzukaT. Pediatric craniofacial trauma. J Oral Maxillofac Surg.2008; 66:58-64. DOI: 10.1016/j.joms.2007.04.023

14. Karim T, Khan AH, Ahmed SS. Trauma of facial Skeleton in children: an Indian perspective. Indian J Surg. 2010; 72:232-235. DOI:10.1007/ s12262-010-0056-x

15. Gassner R, Tuli T, Hachl O, Rudisch A, Ulmer H. Craniofacial trauma: a review of 9543 cases with 21,067 injuries in 10 years. J Craniomaxillofac Surg. 2003; 31:51. DOI: 10.1016/s1010-5182

16. Holland AJ, Broome C, Steinberg A, Cass DT. Facial fractures in children. Pediatr Emerg Care. 2001; 17(3):157-160. DOI:10.1097/ 00006565-200106000-00002

17. Bamjee Y, Lownie JF, Cleaton-Jones PE,Lownie MA. Maxillofacial injuries in a group of South Africans under 18 years of age. $\mathrm{Br} \mathrm{J}$ Oral Maxillofac Surg.1996; 34:298. DOI:10.1016/s0266-4356(96)90006-6

18. Posnik JC, Wells M, Pron GE. Pediatric facial fractures: evolving pattern of treatment. J Oral Maxillofac Surg. 1993; 51:836. DOI:10.1016/s0278-2391(10)80098-9

19. Qudah MA, Bataineh $A B$. A retrospective study of selected oral and maxillofacial fractures in a group of Jordanian children. Oral Surg Oral Med Oral Pathol Oral Radiol Endod.2002;94:310. DOI:10.1067/ moe.2002.127406

20. Kambalimath HV, Agarwal SM, Kambalimath DH, Singh M, Jain M, Jain $\mathrm{N}$, Michael P. Maxillofacial Injuries in Children: A 10 year Retrospective Study. J Maxillofac Oral Surg.2013; 12:140-4. DOI: 10.1007/s12663012-0402-6

21. Ogunlewe MO, James $O$, Ladeinde AL, Adeyemo WL. Pattern of paediatric maxillofacial fractures in Lagos, Nigeria. Int J Paediatr Dent. 2006; 16:358-62. DOI: 10.1111/j.1365-263x.2006.00757x

22. Fasola AO, Nyako EA, Obiechina AE, Arotiba JT. Trends in the characteristics of maxillofacial fractures in Nigeria. J Oral Maxillofac Surg. 2003; 61:1140-3. DOI: 10.1016/s0278-2391(03)00671-2

23. Adeyemo $\mathrm{WL}$, Ladeinde $\mathrm{AL}$, Ogunlewe MO, James $\mathrm{O}$. Trends in the characteristics of oral and maxillofacial injuries in Nigeria: A review of the literature. Head Face Med. 2005; 1:7. DOI: 10.1186/1746-160x-1-7

24. Tripathi S, Mishra R, Yadav D, Kandel L, Pahari B, Chhetri P. Pattern of Mandibular Fracture at Universal College of Medical Sciences (UCMS), Bhairahawa, Rupandehi, Nepal. Mod App Dent Oral Health. 2019; 4(2):333-8. DOI: 10.32474/MADOHC.2019.04.000181

25. Kumar AV, Staffenberg DA, Petronio JA, Wood RJ. Bioabsorbable plates and screws in pediatric craniofacial surgery: A review of 22 cases. J Craniofac Surg. 1997 Mar;8(2):97-99. DOI: 10.1097/ 00001665-199703000-00006

26. Haug RH, Cunningham LL, Brandt MT. Plates, screws and children: their relationship in craniomaxillofacial trauma. J Long Term Eff Med Implants. 2003;13(4):271-287 DOI:10.1615/ jlongtermeffmedimplants. v13.i4.20 